\title{
Consideraciones en torno a la narrativa de Edgardo Rivera Martínez
}

\author{
CÉSAR FERREIRA \\ Universidad de Wisconsin-Milwaukee \\ cferr@uwm.edu

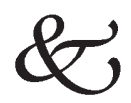

\section{Resumen}

El presente artículo examina el universo narrativo de Edgardo Rivera Martínez. En las letras peruanas contemporáneas, Rivera Martínez es dueño de un universo ficcional con matices propios en el cual uno de sus ejes centrales plantea la necesidad de un diálogo que permita la creación de un nuevo mestizaje en la sociedad peruana. La necesidad de este nuevo mestizaje se forja a través de personajes que se preguntan permanentemente por su identidad y su sentido de pertenencia en el mundo, haciendo evidente la urgencia de una sociedad multicultural donde el mundo andino y el mundo occidental puedan convivir armoniosamente.

Palabras claves: Mestizaje, País de Jauja, Mundo andino, Cosmopolitismo, "Angel de Ocongate".

\begin{abstract}
This article examines the fiction of Edgardo Rivera Martínez. In contemporary Peruvian literature, Rivera Martínez has created a fictional universe in which the central focus calls for the need for dialogue promoting the creation of a new mestizaje in modern Peruvian society. The need for such a focus is born through the creation of characters who permanently question their identities and sense of belonging in the world, making evident the urgency of a new
\end{abstract}


CÉSAR FERREIRA

multicultural society in which the Andean and the Western worlds can coexist in harmony.

Key words: Mestizaje, País de Jauja, Mundo andino, Cosmopolitanism, "Angel de Ocongate".

En una entrevista con el periodista Enrique Planas en el año 2012, Edgardo Rivera Martínez hace la siguiente valoración sobre su obra de ficción:

En mi obra creo haber compartido una propuesta de lo andino que va a lo universal, sin perder nunca su nexo con la raíz. Una obra que incorpora diversas visiones del Perú y del mundo, y que integra algunas formas de introspección. Creo también que he intentado combinar lo poético con lo humorístico, lo realista y lo mágico. Puedo decir que, al escribir mis novelas y cuentos, siento que plasmé lo que me había planteado. Mi obra me ha procurado una gran felicidad. Sobre todo una novela como País de Jauja, que trata sobre la felicidad, el descubrimiento y el amor adolescente. Pero también con la última, $A$ la luz del amanecer, cuyo protagonista parte de la sierra a Praga, a París, a Atenas, a Roma. Y también a México o a la Isla de Pascua. Es una novela que se abre a lo cosmopolita, aunque el protagonista siempre vuelve a sus orígenes. (Planas $\mathrm{C} 2$ ).

El comentario arriba citado, bien podría leerse como una primera puerta de entrada al universo de una obra singular y trascendente en el panorama de la literatura peruana contemporánea. Rivera Martínez no sólo es dueño de una voz y de un universo ficcional propios, que lo han llevado a ocupar un lugar protagónico en nuestras letras, sino que toda su obra puede ser leída como una nueva propuesta de nación para el Perú. En ella, la pequeña ciudad de Jauja, ubicada en la sierra central, se convierte, a partir del mito, la imaginación y la utopía, en un espacio de encuentro de lo andino con lo occidental, vale decir, en un lugar donde es posible forjar un nuevo mestizaje. ${ }^{1}$ A esta propuesta de nación, una temática de grandes alcances en el imaginario nacional del Perú, se suma el cultivo de una prosa cuidada y de gran aliento lírico, a partir de la cual se perfila un personaje prototípico en la obra de Rivera Martínez: un sujeto de corte introspectivo y reflexivo (muchas veces un artista en ciernes), que hurga en su pasado y que, al hacerlo, abandona el mundo realista en el que está instalado para dar rienda suelta a su imaginación y a la aparición de mundos mágicos y fantásticos. Al mismo tiempo, si bien el mundo andino figura como un espacio privilegiado en el universo del escritor jaujino, también es

1 Véase Portocarrero, Gonzalo. "Hacia una auténtica identidad nacional: El nuevo mestizaje". 
importante recalcar el retrato singular que Rivera Martínez hace de la ciudad de Lima, una urbe gris y decadente en la que sus personajes deambulan envueltos en sus propios anhelos y obsesiones. En lo que sigue, quisiera revisar la obra de Rivera Martínez, prestando atención a su evolución y haciendo hincapié en estos ejes temáticos y estilísticos, pues el cultivo recurrente de todos estos elementos da fe de la elaboración de un imaginario propio, cuyo legado y originalidad en la historia de las letras peruanas son innegables.

Rivera Martínez alimentó su vocación por el arte de contar historias desde muy temprano en su vida. Nació en Huancayo en septiembre de 1933 en el seno de una familia de clase media provinciana. Su vida y sus raíces, sin embargo, están profundamente ligadas a Jauja, lugar donde transcurrirá su infancia. Gracias a su familia, el escritor tendrá acceso desde su niñez a una estimulante biblioteca familiar. Al mismo tiempo, su madre le inculcará desde muy temprano en su vida un interés especial por el piano y la música clásica. Asimismo, al ser dueña la familia de unas parcelas de tierra en Ataura, un pueblo en las cercanías de Jauja, Rivera Martínez tendrá ocasión de alternar desde muy pequeño con los campesinos de la zona, a menudo participando de sus faenas agrícolas. Así, el escritor conocerá de cerca y cultivará sus raíces andinas.

En razón de su buen clima, Jauja fue, hasta los primeros años del 1950, un lugar al que acudían desde la segunda parte del siglo XIX enfermos de tuberculosis pulmonar. Muchos de ellos no sólo provenían de Lima, sino también de Europa. Por ello, el viajero francés Charles Wiener, objeto de estudio de más de un libro de Rivera Martínez, pudo decir, hacia 1875, que encontró en su interacción con los habitantes del lugar una pequeña sociedad cosmopolita y cultivada. Todo ese mundo desaparecerá hacia 1947 con el descubrimiento de la estreptomicina, pero todo este rico legado cultural es, sin duda, el que rodea la infancia y juventud de Rivera Martínez.

En Jauja estudió el futuro escritor, primero en la escuela de monjas Nuestra Señora del Carmen y más tarde en el Colegio Nacional de San José, donde terminaría sus estudios de secundaria. En éste último, Rivera Martínez tendrá entre sus profesores al jaujino Pedro S. Monge, un intelectual sanmarquino que había frecuentado a Mariátegui, y cuya influencia resultará decisiva en su futura vocación literaria. Es Monge quien lo alienta a escribir y quien dará a conocer la publicación "La cruz de piedra”, a saber, el primer cuento de Rivera Martínez. ${ }^{2}$

En 1951, Rivera Martínez ingresa a la Universidad Nacional Mayor de San Marcos con la intención de seguir estudios de Derecho, que más tarde abandonará, así como de Literatura. En San Marcos es alumno de Luis Jaime Cisneros,

2 Véase Edgardo Rivera Martínez, "La cruz de piedra”. 
Luis Alberto Sánchez, Jorge Puccinelli y Estuardo Núñez, entre otros ilustres maestros. Sin embargo, será el filólogo Fernando Tola Mendoza quien más influencia tendrá en su formación académica, respondiendo al interés del escritor por el griego y la literatura helénica. La cultura clásica dejará una huella permanente en la formación académica de Rivera Martínez y, de manera más importante, es un elemento recurrente en su conciencia creativa. ${ }^{3}$

En 1957, Rivera Martínez obtiene una beca para continuar sus estudios en La Sorbona. Permanecerá en Francia aproximadamente dos años en lo que será una etapa de gran enriquecimiento vital e intelectual para el escritor. En París, Rivera Martínez profundiza sus conocimientos de literatura griega y de literatura francesa, al tiempo que lleva a cabo un ambicioso trabajo de investigación sobre un tema que lo cautivará siempre: la literatura de viajes. De ese interés surgirán su tesis doctoral, El Perú en la literatura de viaje europea de los siglos XVI, XVII, XVIII, publicada en 1963 por la Facultad de Letras de la Universidad de San Marcos y reeditada por la Fundación Manuel J. Bustamante en el año 2011, así como los estudios que dedicará a los viajeros franceses Léonce Angrand y Charles Wiener, entre otros.

Tras retornar al Perú en 1960, Rivera Martínez ingresa a trabajar a San Marcos, donde es profesor de Literatura Griega y Literatura Francesa. En 1963, es contratado como docente en la Universidad Nacional del Centro, en Huancayo, un hecho que le permite volver a residir en Jauja. De ese año data la aparición de su primer libro de cuentos, El unicornio, un breve volumen que reúne cuatro relatos de temática andina. En el cuento que da título al libro, aparece ese animal fabuloso de la cultura clásica, pero ubicado en un pueblo serrano. Rivera Martínez atribuye esta novedad al gran asombro que causaron en él, años antes, las figuras de unas sirenas presentes en los imafrontes de los templos e iglesias coloniales del Collao. Esculpidas por artistas indígenas durante la Colonia, estas figuras siempre alimentaron la imaginación del escritor y son para él una ilustración clara del entretejimiento cultural (el término es de Rivera Martínez) del que es producto la cultura peruana.

La publicación de El unicornio pasará desapercibida por la crítica. No obstante, el relato puede ser leído como un texto paradigmático de la obra de Rivera Martínez. Y ello no sólo porque "El unicornio" es un cuento que apunta claramente a una fusión del mundo andino y de la cultura occidental, sino porque la voz narrativa en primera persona del relato nos permite el ingreso al mundo privado del protagonista, un maestro de escuela, para perfilar la existencia de un sujeto introspectivo y cultivado. El anónimo protagonista es, además, un

3 Véase Edgardo Rivera Martínez, "Mi deuda con el mundo clásico". 
gran amante de la naturaleza, cuyo carácter mágico y misterioso exaltará una y otra vez en sus muchos paseos por el pueblo. Reflexivo y solitario, el profesor busca siempre conciliar su mundo más inmediato con su admiración por la mitología clásica. Así, al igual que en muchos otros textos de Rivera Martínez, el lector se convierte de pronto en un privilegiado escucha de las tribulaciones afectivas e intelectuales a las que se enfrenta el protagonista. En este caso, no solo será testigo de la súbita aparición del personaje mítico en el apacible pueblo andino del maestro, sino también de su posterior desparición junto con Luscinda, una bella muchacha del pueblo por la cual el protagonista profesa una silenciosa admiración. Así las cosas, la realidad cotidiana y el entorno rural descritos al comenzar el relato no sólo adquieren un súbito matiz mágico y misterioso con la fugaz visita del mítico animal, sino que le ceden su protagonismo a la fantasía. Dicho en pocas palabras, el mundo clásico y el mundo andino son capaces de establecer un punto de encuentro desde el espacio de la imaginación y la fábula. ${ }^{4}$

En 1974, con el sello Ediciones de la Clepsidra, Rivera Martínez publica su primera novela corta, El visitante, un texto de factura notable narrado a través de sucesivos monólogos que se destaca por la presencia de un personaje recurrente en la obra del escritor jaujino: la figura del ángel caído. En esta ocasión, la escritura de Rivera Martínez muestra otra vez aquí una prosa meditada e introspectiva para perfilar un protagonista de características muy peculiares. Asimismo, como ocurre en "El unicornio, el realismo inicial del relato pronto le cede su lugar a lo fantástico y enigmático, al tiempo que el espacio neblinoso del malecón limeño contribuye a subrayar el carácter misterioso del anónimo protagonista. Como muchas criaturas del autor, éste es un ser solitario y vagabundo que un día se topa con Lena en uno de sus largos paseos por un malecón limeño. El extraño sujeto es "dueño de una belleza singular, con algo de andrógino que turba y sorprende", así como de "una antigua y ya desusada gentileza" (95). ${ }^{5}$ La voz lacónica del protagonista (que se alterna por momentos con las de Lena y Fernando, el esposo de ésta) insinúa con sutileza los deseos más escondidos del protagonista, uno de los cuales parece ser una velada intención amorosa con Lena. Sin embargo, este deseo nunca se manifiesta abiertamente pues, junto a una elegante caballerosidad, el visitante también exhíbe una conciencia entre dubitativa y herida. Marcado por una gran tensión psicológica, el final abierto del relato invita al lector a meditar sobre el futuro del solitario visitante, un ser que parece transitar por el mundo sin un destino fijo, en una suerte de gran limbo existencial. Por ello, no es de extrañar que,

4 Sobre El unicornio véase el análisis de Elton Honores en su libro Mundos imposibles: Lo fantástico en la literatura peruana.

5 Cito aquí por la edición de Ciudad de fuego. Lima: Alfaguara, 2000.

LETRAS 86 (124), 2015 
tras su despedida de Lena, éste confiese sentirse como una especie de "Lobo que vaga por países y ciudades, en inútil búsqueda del quantum que pudiera llevarlo, alguna vez, al sueño, a la extinción o la nada" (127). ${ }^{6}$

En 1978, aparece el siguiente libro de Rivera Martínez, Azurita, editado bajo el sello Lasontay. Se trata de un volumen de ocho relatos que prologa Antonio Cornejo Polar y que, además de los cuatro cuentos previamente publicados en El unicornio, incluye un cuento de notable factura lírica, "Amaru", un relato que confirma la maestría de Rivera Martínez en el género breve. En verdad, más que un cuento propiamente dicho, "Amaru" es un gran relato-poema. En esta ocasión, el autor se sirve de su conocimiento de la tradición oral andina para pergeñar un texto donde la mítica sierpe andina, que aparece aquí encerrada entre las paredes de un viejo palacio cuzqueño en ruinas, mantiene un largo diálogo consigo misma. En el relato, el constante desdoblamiento de la voz que lo informa entre una primera y una segunda persona narrativa se complementa con la incorporación de un fino juego de espejos, ese elemento tan caro a la ficción de Borges, para multiplicar las dimensiones de la realidad hasta instalar el relato en el mundo del mito. Poco a poco, las voces que forjan el relato van hurgando en el origen sagrado de este ser fabuloso que medita de manera dubitativa y atribulada sobre su posible destino en la cosmogonía andina. Y es que desde la frase inicial del relato, queda claro que el viejo esplendor de la mítica sierpe y el poder que alguna vez ejerció sobre el mundo andino ahora se extinguen irremediablemente: "Sombra soy de la penumbra-dice-, pero arde en mí un fuego. Un fuego cuyo fin se aproxima” (Rivera Martínez, Cuentos completos 106), dice el narrador. Es en ese contexto que adquiere un simbolismo particular el hecho de que la serpiente ahora se encuentre encerrada entre las paredes de un viejo palacio cuzqueño, pues el ruinoso recinto, si bien alguna vez albergó el ejercicio de poder y riqueza en la capital del incanato, ahora no es más que un espacio que simboliza un mundo perdido; esto es, un lugar que cobija en silencio un pasado de esplendor ahora desaparecido. El final abierto del texto no solo subraya un doloroso sentido de pérdida, producto de la fractura existente entre el mundo andino y el mundo español, sino que las tribulaciones expresadas por la agónica voz del amaru son una suerte de reclamo por rescatar, a partir de la memoria y el mito, los diversos mundos que se cruzan en el devenir histórico peruano y su imaginario colectivo. ${ }^{7}$

El rigor del lenguaje narrativo de Rivera Martínez, así como su singular tono expresivo, son algunas de las virtudes que señala Alfredo Bryce Echenique

6 Véase Cueto, Alonso. "Edgardo Rivera: El visitante" y Escobar, Alberto. "El visitante a deshora".

7 Véase al respecto González Vigil, Ricardo. "Edgardo Rivera Martínez y lo real maravilloso en el Ande” y Bueno Chávez, Raúl. "Azurita”. 
en la presentación del siguiente libro de Rivera Martínez, Enunciación, un volumen que aparece con el sello Lasontay en 1979. Se trata de un libro que reúne, además de un cuento inedito, contiene las dos novelas cortas escritas hasta ese momento por el escritor, a saber, "El visitante" y "Ciudad de fuego", así como el relato que le da título al volumen. En estos tres textos, el desarraigo, la meditación filosófica y la utopía comparten un mismo espacio con la elaboración de un retrato misterioso y gris de la ciudad de Lima. ${ }^{8}$ En 1981, Rivera Martínez publica en un volumen independiente el relato Historia de Cifar y de Camilo, un texto que parece pertenecer a los ámbitos de la literatura infantil, sobre todo si nos atenemos a la inocencia de sus personajes y al tierno candor de la mirada de éstos sobre la realidad limeña. Bien leído, sin embargo, encierra además una sutil denuncia sobre la estratificada dinámica social peruana. ${ }^{9}$

En 1982, el semanario Caretas organiza la primera versión de su concurso "El cuento de las mil palabras". Entre cientos de participantes, Rivera Martínez surge como ganador con uno de sus relatos más emblemáticos, "Angel de Ocongate", un texto que combina con maestría la figura del ángel caído y el intenso lirismo su prosa. El relato le servirá a Rivera Martínez para dar a la imprenta en 1986 Angel de Ocongate y otros cuentos, un volumen que publica la editorial Peisa y que combina cuentos tanto de temática andina como urbana. "Angel de Ocongate" es probablemente el relato más antologado de Rivera Martínez y uno de los textos que mejor sintetiza una de las grandes preocupaciones de su universo literario: el dilema de la identidad en el Perú y la necesidad de reafirmar su carácter mestizo. Estamos ante un nuevo soliloquio que hurga dramáticamente en la conciencia de un ser escindido: "Quién soy sino apagada sombra en el atrio de una capilla en ruinas, en medio de esta puna inmensa" (19), se pregunta su protagonista al inicio del relato. El protagonista es un sujeto vagabundo y trashumante que, desde un principio, se identifica como un ángel caído; sin embargo, pronto aprendemos que el protagonista se reconoce también como un antiguo danzante de tijeras del mundo andino. Por ello, a la mención de una capilla en ruinas en medio de la inmensa puna del inicio del relato se suma la mención del nombre Ocongate en el título del cuento, lo que nos remite a la geografía del Cusco, concretamente a Quispicanchis y a las faldas del nevado Ausangate. El nevado es un lugar de gran simbolismo en la cultura andina, pues es también un espacio de encuentro para los bailarines andinos durante las festividades del señor de Q'oyur Riti. No obstante, la condición angelical del protagonista también remite la identidad del narrador a una raíz de evidente carácter católico y, por tanto, hispánica. La fractura en

8 Véase González Vigil, Ricardo. "Rivera Martínez: Ciudad y fuego".

9 Véase Niño de Guzmán, Guillermo. "Historia de Cifar y de Camilo". 
César Ferreira

su identidad se torna más dramática cuando un hombre viejo en el tambo de Raurac le informa al viajero que su figura de danzante fue registrada de forma permanente en una imagen en "La capilla de Santa Cruz, en la pampa de Ocongate" (21). Por eso, a manera de reclamo, el viejo es quien también le recuerda a la angelical figura que éste se ha vuelto un "bailante sin memoria" (21) para los habitantes del mundo andino, vale decir, un sujeto que parece haber olvidado su pasado. Todo este acontecer explica su presente angustia, así como la pena que éste purga como un ser errante. Dicho de otra manera, la voz del narrador se debate entre la búsqueda de una identidad y un lugar de reposo, pues tiene clara "la conciencia de algún tipo de pérdida fundacional," como bien han afirmado Cynthia y Víctor Vich (164). La pérdida de esa raíz inicial se presenta ahora como irrecuperable, de allí el viaje sin rumbo que parece haber emprendido el protagonista. Como en "Amaru", "Angel de Ocongate" plantea que el dilema de "la identidad en el Perú es una dialéctica no resuelta entre los sujetos y su historia" (166), es decir, una fractura que solo podrá resolverse a partir de la existencia de una nueva identidad mestiza. Mientras ello no ocurra, el "ansioso y febril" (19) narrador de este gran relato está condenado a preguntarse una y otra vez por su verdadera identidad y a deambular sin destino por la inmensa puna.

Aparecida bajo el sello La Voz Ediciones, la publicación de País de Jauja en 1993 constituye uno de los hechos más significativos de nuestra historia literaria reciente y ubica a Rivera Martínez en un sitial protagónico en nuestras letras. Perteneciente al género de la novela de aprendizaje, País de Jauja narra los tres meses de vacaciones escolares del adolescente Claudio Alaya Manrique en el verano de 1947, en un momento decisivo de su formación como individuo. La rica voz del relato se reparte entre el instrospectivo soliloquio en segunda persona de Claudio y la voz directa y confesional en primera persona de su diario íntimo. A través de la figura del protagonista, el relato da cuenta de los dilemas más viscerales que éste enfrenta en su transición de la niñez a la adolescencia. Y es que leída con cuidado, toda la trama de País de Jauja radica, de un lado, en la toma conciencia del protagonista de su origen andino y, de otro, en su paulatino descubrimiento y aceptación de otros espacios pertencientes al mundo occidental. No son pocas las ocasiones en que este mundo, para Claudio, representa la convergencia de mundos en conflicto; pero en ese conflicto radica precisamente el núcleo ideológico de la novela y la convicción más personal de su autor, esto es, la necesidad de un consenso que reconozca que el único modelo viable de nación es aquel que valide la convivencia de las diversas tradiciones culturales que constituyen la identidad peruana. 
Los elogios a la novela de Rivera Martínez no tardaron en llegar ${ }^{10}$. Y es que, entre sus muchas virtudes, País de Jauja es una novela que rompe con una visión estereotipada del mundo andino peruano, siempre dura y dolorosa, sobre todo si nos atenemos a los antecedentes más conocidos como los de Ciro Alegría o de José María Arguedas. Bajo la mirada de Rivera Martínez, en cambio, Jauja se transforma en un lugar de encuentro entre el Ande y el mundo occidental, un idílico espacio donde conviven en cordial armonia personajes de variada procedencia. De hecho, a la familia más directa del protagonista -compuesta por su madre, su hermano Abelardo, su hermana Laura y la tía Marisa-, se suman una serie de personajes pintorescos como Ismena y Euristela de los Heros, dos tías viejas que alguna vez fueron mujeres codiciadas en el pueblo debido a la fortuna de su padre, y otros jaujinos oriundos, como Palomeque y Mitrídates. A ellos se unen los personajes europeos, como el excéntrico Radulescu, o la bella Elena Oyarguren, cuya figura es un contrapunto con la de Zoraida Awapara, con quien Claudio se inicia sexualmente. Y también está Leonor, una muchacha campesina con la que el protagonista vivirá un intenso romance. En País de Jauja, una narración de gran intensidad plasma un ambicioso proceso de transculturación y hace posible que la leyenda de los amarus comparta un mismo espacio con los mitos clásicos griegos; que la música de Bach se escuche junto a los ritmos andinos; y que los yaravíes compartan un mismo escenario con la poesía de Vallejo. En medio de este mestizaje nuevo y gozoso (si bien a veces tenso), la mirada inquisitiva de Claudio le abre el paso a un diálogo múltiple y enriquecedor entre los muchos personajes del libro, cuyas aventuras a menudo serán matizadas por finos toques de ironía y humor. Destaquemos, asimismo, el trabajado lirismo de la prosa de Rivera Martínez, un discurso que, en definitiva, ayuda a la configuración de un mundo de nostalgia pero también de una gran plenitud vital.

Claudio es un sujeto nuevo al final de este tránsito de la niñez a la adolescencia, un largo y vibrante tour de force, que lo convierte en un personaje que enfrentará al mundo con una nueva conciencia como individuo. Claudio no solo es alguien con un profundo arraigo a sus raíces andinas, sino que también se sabe miembro y partícipe de un mundo más vasto y multicultural. Gracias a este libro, Jauja es un espacio mítico para el imaginario peruano de nuestros días porque, desde su convicción optimista, la novela reclama un mestizaje

10 Entre los primeros comentarios que se publicaron sobre la novela destaco, entre otros, los siguientes: Cornejo Polar, Antonio. "Nombre de país: el nombre"; Garayar, Carlos. "Elogio y elegía de la adolescencia: País de Jauja"; Martos, Marco. "Rivera Martínez, un orfebre de la palabra". Véanse también los estudios de Carlos Garayar "País de Jauja" y Mary Beth TierneyTello "Lo nuestro y lo femenino: la identidad local y la mujer en País de Jauja de Edgardo Rivera Martínez". 
nuevo, es decir, un mundo donde convivan armoniosamente lo cosmopolita con lo autóctono y lo tradicional con lo moderno. Bien leída, la de Rivera Martínez es una propuesta de fidelidad a las raíces y de aceptación de los aportes de otras tradiciones culturales; esto es, de una modernidad matizada por el fenómeno de la globalización; pero una globalización bien entendida, consciente de su inevitable apertura a otros horizontes culturales, y atenta, al mismo tiempo a todas las amenazas que esta apertura implica para las múltples identidades regionales del Perú en su proyecto posible como nación.

Jauja será también el escenario de la siguiente novela de Rivera Martínez, Libro del amor y de las profecías, una nueva novela larga y ambiciosa publicada por Peisa y Arango Editores en 1999. En ella, Juan Esteban Uscamayta protagoniza un relato de largo aliento, donde las líneas argumentales pertenecen a órdenes diversos, y van desde lo sobrenatural y lo sublime, hasta lo erótico y lo cómico. Ello permite que el libro sea no sólo una suerte de gran comedia de costumbres provincianas, con una rica galería de personajes, sino que sirva para que Jauja sea una vez más el escenario para la experiencia afectiva y la búsqueda existencial del protagonista. Todo ello en medio de una prosa siempre cadenciosa, múltiple y proteica, donde el goce por contar nutre su rica trama. ${ }^{11}$

Con la llegada del nuevo siglo, la obra de Rivera Martínez siguió creciendo de manera significativa. Recordemos, por ejemplo, una nueva edición de sus novelas cortas del año 2000, un volumen que, además de ofrecernos versiones definitivas de El visitante y Ciudad de fuego, incluye también el relato inédito Un viejo señor en la neblina. Es éste un texto de impecable factura, que no solo revive el mito de Icaro sino que confirma el singular retrato que plasma la escritura del autor de una Lima entre gris y vetusta que ya antes asomó en su cuentística. ${ }^{12}$ Recordemos, asismismo, la edición completa de todos los cuentos de Rivera Martínez, publicada el año 2008 con el título de Cuentos del ande y la neblina. Este nuevo volumen incluye su última colección de relatos, Danzantes de la noche y de la muerte, que apareció poco antes ese mismo año, y donde la impronta de lo fantástico se manifiesta de manera magistral en el relato que le da título al volumen. ${ }^{13}$

La tercera novela de Rivera Martínez, Diario de Santa María, data del año 2009. En ella, el escritor vuelve a explorar la feliz conjunción de la cultura occidental y las tradiciones andinas a través del diario íntimo de la joven Felicia de

11 Véase Castañeda, Luis Hernán. "Los lazos de la autoría: Las novelas de Edgardo Rivera Martínez".

12 Véase Ferreira, César. "La Lima de Edgardo Rivera Martínez: Notas a Ciudad de fuego".

13 Véase Rabí Do Carmo, Alonso. "Cuentos de la noche y de la muerte". 
los Ríos, la inquisitiva alumna de un internado de monjas ubicado en la sierra central. El texto sortea con creces el reto de narrar desde una voz femenina los avatares de una adolescente y su despertar sexual. Como otros personajes del autor, Felicia es una aprendiz de escritora. Por ello, el verdadero eje de la novela es la constitución de su universo poético, entendido éste como una expresión de su formación afectiva y personal. En verdad, en los muchos intercambios vitales y todas las peripecias que la novela narra entre Felicia y Solange prima el deleite de una identidad juvenil, así como el asombro que casua el paulatino descubrimiento del mundo. Todo ello en medio de las voces de Vallejo y Eguren, de Safo y García Lorca, así como de los ritmos musicales del yaraví y la tunantada, entre muchos otros. ${ }^{14} \mathrm{Y}$ para establecer nuevos vasos comunicantes a su mundo novelístico, recordemos finalmente a Mariano de los Ríos, el protagonista de la novela más reciente de Rivera Martínez, A la luz del amanecer, aparecida en Alfaguara en 2012. En ella, el protagonista retorna, tras muchos años de ausencia, a la casa familiar de Soray, un pueblo en el valle del Mantaro. Allí, entre el sueño y la vigilia, pasa revista a su vida y dialoga con los fantasmas de sus amigos, sus parientes y sus antepasados, así como con las mujeres que amó. Si la nostalgia y la melancolía marcan el tono general de este relato, no es menos cierto que Rivera Martínez también subraya, a través de la figura de Mariano, su apuesta por el diálogo y la fusión armoniosa de la cultura andina con la occidental, pues éste tal vez sea el más cosmopolita de todos sus personajes hasta la fecha. ${ }^{15}$

Edgardo Rivera Martínez es, en suma, dueño de un universo propio en la historia de nuestra literatura. A través de una prosa de gran aliento lírico, el autor no sólo ha logrado escribir e inscribir a la ciudad de Jauja en el imaginario colectivo de nuestras letras, sino que su obra toda continúa apostando con inusitado optimismo por un Perú multicultural; esto es, una nación posible, capaz de convocar a actores de diversa procedencia a un diálogo armonioso y enriquecedor desde el viejo arte de la fábula. Un arte que este gran contador de historias cultiva con gran maestría.

\section{Referencias bibliográficas}

BUENO CHAVEZ, Raúl (1978) “Azurita” en Revista de crítica literaria latinoamericana 7-8; pp. 224-226.

CASTANEDA, Luis Hernán (2012) "Los lazos de la autoría: Las novelas de Edgardo Rivera Martínez” en Artes \& Letras 54-55; pp. 27-29.

14 Véase Pollarolo, Giovanna. "El cuaderno de Felicia”.

15 Véase Sánchez Hernani, Enrique. "A la luz de amanecer: Ensueño y memoria”.

LETRAS 86 (124), 2015 
CORNEJO POLAR, Antonio (1993) "Nombre de país: el nombre" en Sí, Lima, 5 de julio; pp. $42-43$.

CUETO, Alonso (1976) "Edgardo Rivera: El visitante" en el suplemento "La Imagen" de La Prensa, Lima, 30 de mayo; pp. 22.

ESCOBAR, Alberto (1974) "El visitante a deshora" en Correo, Lima, 21 de setiembre; pp. 11.

FERREIRA, César (2010) "La Lima de Edgardo Rivera Martínez: Notas a Ciudad de fuego". En: Martín-Revista de Artes y Letras 23; pp. 37-41.

GARAYAR, Carlos (1994). "Elogio y elegía de la adolescencia: País de Jauja". "Revista" de El Peruano, Lima, 3 de enero; p. 5.

GARAYAR, Carlos (2010). "País de Jauja”. En: Martín-Revista de Artes y Letras 23; pp. 61-65.

GONZALEZ VIGIL, Ricardo (2006) "La danza del misterio" en El Comercio, Lima, 13 de abril; p. C4.

GONZALEZ VIGIL, Ricardo (1979) "Rivera Martínez: Ciudad y fuego". En "Suplemento Dominical” de El Comercio, Lima, 11 de marzo; p. 17

GONZALEZ VIGIL, Ricardo (1978) "Edgardo Rivera Martínez y los real maravilloso en el ande" en "Suplemento Dominical" de El Comercio, Lima, 2 de abril; p. 17.

HONORES VASQUEZ, Elton (2010). Mundos imposibles: lo fantástico en la narrativa peruana. Lima: Cuerpo de la Metáfora.

MARTOS, Marco (1993). Rivera Martínez: un orfebre de la palabra” en Gestión, Lima, 14 de octubre; p. 18.

NIÑO DE GUZMAN, Guillermo (1982). "Historia de Cifar y de Camilo" en Cielo Abierto 22; pp. 61-62.

POLLAROLO, Giovanna (2009) "El cuaderno de Felicia” en Hueso húmero 53; pp. 218-221.

PORTOCARRERO, Gonzalo (2013) "Hacia una auténtica identidad nacional: El nuevo mestizaje" en El Comercio, Lima, 18 de mayo; p. A26.

PLANAS, Enrique (2012) "Palabras de un escritor feliz: Entrevista a Edgardo Rivera Martínez” en El Comercio, Lima, 27 de julio; p. C2.

RABI DO CARMO, Alonso (2006) "Cuentos de la noche y de la muerte" en "El Dominical" de El Comercio; p. 12.

RIVERA MARTINEZ, Edgardo (1999) Cuentos completos. Lima: Alfaguara.

RIVERA MARTINEZ, Edgardo (2000) Ciudad de fuego. Lima: Alfaguara.

RIVERA MARTINEZ, Edgardo (1950) "La cruz de piedra" en Xauxa-Organo del Colegio Nacional de San José IX, 17; pp. 22-25.

RIVERA MARTINEZ, Edgardo (1998) "Mi deuda con el mundo clásico" en Encuentro Internacional Narradores de esta América. Lima: Universidad de Lima/Fondo de Cultura Económica; pp. 71-74.

SANCHEZ HERNANI, Enrique (2012) "A la luz de amanecer: Ensueño y memoria” en "Somos” de El Comercio, 28 de abril; p. 16. 
TIERNEY-TELLO, Mary Beth (2006) "Lo nuestro y lo femenino: la identidad local y la mujer en País de Jauja de Edgardo Rivera Martínez”. En: Edgardo Rivera Martínez: Nuevas lecturas. Lima: Fondo Editorial UNMSM. César Ferreira, editor; pp. 183198.

VICH, Cynthia y Víctor VICH (2001). "'La taciturna corriente que me absorbe”: "Angel de Ocongate” y el problema de la identidad (en el Perú). En: Revista de crítica literaria latinoamericana 54; pp. 163-169. 